http://dx.doi.org/10.32929/2446-8355.2019v28n1p50-64

\title{
EFEITO ALELOPÁTICO DE Pityrocarpa moniliformis NA GERMINAÇÃO DO SORGO SACARINO E PLANTAS DANINHAS
}

Bruno França da Trindade Lessa ${ }^{*}$, Maria das Neves de Andrade $^{2}$, Mirella Rodrigues Antunes $^{2}$, Ariel Marques Reges ${ }^{2}$, Ericles da Silva Medrado ${ }^{2}$, Igor Souza de Oliveira ${ }^{2}$

\footnotetext{
${ }^{1}$ Professor Adjunto, Curso de Engenharia Agronômica, Universidade Federal do Vale do São Francisco, Petrolina, Pernambuco, Brasil. *E-mail do autor correspondente: bruno.ftlessa@ univasf.edu.br

${ }^{2}$ Graduando em Engenharia Agronômica, Universidade Federal do Vale do São Francisco, Petrolina, Pernambuco, Brasil.
}

Recebido: 23/10/2018; Aceito: 09/04/2019

\begin{abstract}
RESUMO: Com o interesse e incentivo pelos sistemas integrados de atividades agropecuárias, se faz necessário melhor conhecer as relações entre os vegetais que serão manejados no mesmo espaço e tempo. Assim, o objetivo deste trabalho foi avaliar o efeito do extrato aquoso da espécie Pityrocarpa moniliformis na germinação da espécie cultivada Sorghum bicolor (sorgo tipo sacarino) e das plantas daninhas Emilia fosbergii e Bidens pilosa. Foram produzidas soluções por infusão de folhas e ramos de $P$. moniliformis nas concentrações de $0,25,50,75$ e $100 \mathrm{~g} \mathrm{~L}^{-1}$. As soluções foram utilizadas em testes de germinação para as três espécies-alvo, sendo avaliados a porcentagem, o índice de velocidade e o tempo médio de germinação, além do comprimento e massa de matéria seca de parte aérea, raiz e total das plântulas do sorgo. Os dados obtidos foram submetidos a análise de variância com teste de Tukey (5\%) e regressão. Houve diminuição em 18,5\% da porcentagem de germinação para $B$. pilosa, e menor índice de velocidade para as três espécies em função das concentrações do extrato. Para o sorgo sacarino a produção de plântulas normais foi prejudicada drasticamente, decrescendo com o aumento das concentrações do extrato e chegando a zero quando da dosagem de $74 \mathrm{~g} \mathrm{~L}^{-1}$. O extrato aquoso de folhas e ramos de $P$. moniliformis causa retardamento no processo germinativo das sementes de B. pilosa, E. fosbergii e do sorgo sacarino, causando deformação em plântulas neste último.
\end{abstract}

Palavras-chave: Sorghum bicolor. Catanduva. Sementes.

\section{ALLELOPATHIC EFFECT OF Pityrocarpa moniliformis IN THE GERMINATION OF SWEET SORGHUM AND WEEDS}

\begin{abstract}
With interest and incentive in the integrated systems of agricultural activities, it is necessary to know better the relations between plant populations that are managed in the same space and time. Therefore, the objective this work was evaluate the effect of the aqueous extracts of Pityrocarpa moniliformis in the germination of Sorghum bicolor (sweet sorghum) and of the weeds Emilia forbergii and Bidens pilosa. Were produced soluble extract by infusion of leaves and fine branches of $P$. moniliformis, concentrations of $0,25,50,75$ and $100 \mathrm{~g} \mathrm{~L}^{-1}$. The solutions were used in germination tests with target species determining percentage, speed index and average time of germination, beyond the sorghum seedlings
\end{abstract}


length and dry matter (shoot, root and total). The data were submitted to variance analysis, Tukey test (5\%) and regression. There was germination decrease in $18.5 \%$ to B. pilosa, and lower speed index to target species as a function extract concentration. The normal seedling production of sweet sorghum was drastically impaired, reaching zero when the concentration of $74 \mathrm{~g} \mathrm{~L}^{-1}$. The aqueous extract of leaves and branches of $P$. moniliformis causes retardment in B. pilosa, E. fosbergii and sweet sorghum germination process, with deformation in the sorghum seedlings.

Key words: Sorghum bicolor. Catanduva. Seeds.

\section{INTRODUÇÃO}

Em uma comunidade vegetal os fatores bióticos e abióticos influenciam a distribuição, abundância e a perpetuação das espécies. Indivíduos de mesma espécie ou de espécies diferentes podem ter influências uns sobre os outros, que podem ter caráter benéfico ou prejudicial.

Um fenômeno fundamental nessas relações trata-se da alelopatia, caracterizada pela liberação de compostos pelas plantas, denominados aleloquímicos. A alelopatia é um tipo de interação onde moléculas químicas, produzidas principalmente pelo metabolismo secundário vegetal, são liberadas no ambiente e acarretam alterações, muitas vezes prejudicais, no desenvolvimento de uma outra planta. Esses compostos podem ser produzidos em qualquer parte da planta, desde a raiz até as folhas, podendo ser liberados por tecidos vivos ou mortos. A intensidade pela qual a espécie afetada passará a sofrer dependerá da quantidade e/ou concentração desses compostos no ambiente (SILVA; SILVA, 2007; SOUZA FILHO, 2014).

O conhecimento sobre estas relações vegetais toma uma importância ainda maior no tocante aos sistemas integrados de produção agropecuária, que tem como finalidade associar, em uma mesma área, atividades agrícolas, pecuárias e florestais, seja em consórcio, concessão ou até mesmo rotação. Os sistemas integrados subdividem-se em 4 grupos: Agripastoril ou Integração Lavoura-Pecuária (ILP), Silvipastoril ou Integração Pecuária-Floresta (IPF), Silviagrícola ou Integração Lavoura-Floresta (ILF) e o Agrissilvipastoril ou Integração Lavoura-Pecuária-Floresta (ILPF) (BALBINOT JÚNIOR. et al., 2009).

Os sistemas integrados são atividades ainda em ascensão no Brasil, e encontram-se pouco desenvolvidos tecnologicamente na região semiárida brasileira. Menor foco ainda é dado ao componente silvicultural, apesar da rica flora nativa, com presença de importantes espécies arbóreas passíveis de manejo. Entre estas espécies, cita-se a Pityrocarpa moniliformis (Benth.) Luckow \& R. W. Jobson, pertencente à família Fabaceae e conhecida como angico-de-bezerro ou catanduva (BENEDITO, 2010). Esta espécie é utilizada na alimentação animal, e apresenta importância apícola e madeireira, além de ser uma opção para inícios de reflorestamentos pelo seu rápido crescimento e rusticidade (AZEREDO et al., 2010). Todavia, é comum espécies da família Fabaceae, nativas do bioma Caatinga, apresentar altos níveis de compostos secundários como alcalóides, flavonóides e cumarinas (alto potencial alelopático), já que esta característica é importante para a defesa vegetal principalmente em ambientes adversos (RIBEIRO; KAPLAN, 2002). 
No tocante ao componente agrícola (lavoura), o cultivo do sorgo apresenta-se como uma atividade de alto valor para a região nordeste, principalmente no sertão. A cultura tolera as condições extremas comuns e ainda possui diferentes potencialidades dependendo do genótipo, citam-se os cultivares graníferos, forrageiros e sacarinos. Este último, promissor para o avanço do setor energético, já que se trata de uma fonte alternativa para a produção de etanol (DURÃES et al., 2012).

Neste sentido, investigações que tragam informações a respeito das interações vegetais interespecíficas são importantes para nortear possíveis estratégias de manejo dentro dos sistemas de produção integrados. Tais informações garantirão o sucesso ou o fracasso de empreendimentos agropecuários que pretendem utilizar os conceitos dos sistemas diversificados na região semiárida, região essa carente de modelos eficientes de produção integrada.

No ambiente agrícola, outro tipo de comunidade vegetal se destaca podendo intervir nas relações entre espécies; trata-se da comunidade infestante, que segundo Pitelli (2015) é o conjunto de todas as populações de plantas daninhas que infestam as áreas agrícolas, pastagens, pomares e reflorestamentos. A presença destas plantas pode trazer diversos tipos de prejuízos aos componentes de produção de um sistema integrado, entre eles: diminuir a produtividade da lavoura e/ou floresta em decorrência de competição por recursos do meio (água, nutrientes, luz e etc.); e pela liberação de compostos alelopáticos comuns nestas plantas, algumas substâncias podem ainda ocasionar a morte de animais quando de sua ingestão (LORENZI, 2008).

O fenômeno da alelopatia é, portanto, considerado como um dos grandes fatores de interferência de plantas daninhas. Por outro lado, poderá ser um aliado no manejo fitossanitário sustentável já que tais substâncias parecem promissoras como herbicidas naturais. Assim, o objetivo do presente trabalho foi avaliar os efeitos do extrato aquoso de Pityrocarpa moniliformis (Benth.) Luckow \& R.W. Jobson sobre o processo germinativo e vigor de sementes da espécie cultivada Sorghum bicolor (tipo sacarino) e das plantas daninhas Emilia fosbergii Nicolson e Bidens pilosa L.

\section{MATERIAL E MÉTODOS}

O trabalho foi conduzido no Laboratório de Sementes e Manejo de Flora (LASMAF) da Universidade Federal do Vale do São Francisco (UNIVASF), em Petrolina-PE, latitude 09²3'55"S e longitude 40³0'03" W e ocorreu entre os meses de maio e julho de 2017.

As coletas dos aquênios/sementes das duas espécies de plantas daninhas, E. fosbergii e B. pilosa, foram realizadas manualmente de infestações naturais da espécie em ambientes agrícolas no setor de produção vegetal do Centro de Ciências Agrárias da UNIVASF. As sementes da espécie cultivada Sorghum bicolor, variedade BRS 506 (tipo sacarino), foram obtidas comercialmente junto à Embrapa Produtos e Mercado/Escritório de Sete Lagoas, MG.

Foram realizados testes iniciais com os aquênios/sementes das três espécies para conhecimento do padrão germinativo inicial dos lotes. Para isso, os aquênios das plantas daninhas e sementes do sorgo foram colocados, respectivamente, em caixas 'gerbox' 
contendo papel 'germitest' e rolos de papel, umedecidos com água destilada com o volume correspondendo à três vezes o peso do papel e acondicionados em câmeras B.O.D. com temperatura e fotoperíodo controlados. Os rolos de papel foram mantidos em sacos de polietileno para minimizar a perda de água e permaneceram na BOD em posição vertical. Para o sorgo sacarino, a temperatura utilizada foi de $25^{\circ} \mathrm{C}$ com fotoperíodo de $12 \mathrm{~h}$, sendo avaliada a porcentagem de germinação aos 10 dias após semeadura. Foram consideradas germinadas as sementes que produziram plântulas com todas as partes essenciais visíveis e consideradas normais (BRASIL, 2009). Para as plantas daninhas, a temperatura foi de $30^{\circ} \mathrm{C}$ com $12 \mathrm{~h}$ de fotoperíodo sendo determinada a porcentagem de germinação no $21^{\circ}$ dia após a semeadura e consideradas germinadas quando das plântulas com folhas primárias visíveis (LESSA et al., 2013). Os lotes apresentaram as seguintes porcentagens de germinação: 89,5; 76,3 e 85,0 \%, respectivamente, para as espécies sorgo sacarino, B. pilosa e E. forbergii.

As amostras de P. moniliformis foram coletados de diferentes árvores adultas seccionando folhas e ramos finos $(10 \mathrm{~mm})$. Em seguida esse material foi triturado, utilizando uma máquina forrageira, e deixados por três dias à sombra para secagem natural. $\mathrm{O}$ material foi selecionado e quantificado para preparo das soluções através de infusão em água destilada por um minuto após fervura, nas doses de $25,50,75$ e $100 \mathrm{~g} \mathrm{~L}^{-1}$.

As diferentes soluções, assim como a água destilada utilizada, foram submetidas à determinação do potencial hidrogeniônico $(\mathrm{pH})$, teor de sólidos solúveis totais ( ${ }^{\circ}$ Brix) e condutividade elétrica (CE) para caracterização química parcial das soluções (Tabela 1). Para isso, foram utilizados pHgâmetro de bancada, refratômetro portátil graduado $\left(0-32^{\circ}\right.$ Brix $)$ e condutivímetro também portátil, respectivamente.

Tabela 1. Condutividade elétrica (CE), pH e sólidos solúveis totais (SST) das soluções a base de folhas e ramos de Pityrocarpa moniliformis. Electric conductivity (EC), pH and total soluble solids (TSS) of the solutions based on leaves and branches of Pityrocarpa miniliformis.

\begin{tabular}{cccc}
\hline Conc. $\left(\mathrm{g} \mathrm{L}^{-1}\right)$ & $\mathrm{pH}$ & $\mathrm{SST}\left({ }^{\circ}\right.$ Brix $)$ & $\mathrm{CE}\left(\mathrm{dS} \mathrm{m}^{-1}\right)$ \\
\hline 0 & 5,70 & 0,0 & 0,00 \\
25 & 5,72 & 0,3 & 0,86 \\
50 & 5,26 & 0,4 & 1,71 \\
75 & 5,24 & 1,1 & 2,57 \\
100 & 5,22 & 1,4 & 3,06 \\
\hline
\end{tabular}

Conc.: concentrações. Conc.: concentrations.

Para a implantação do experimento, os aquênios das espécies daninhas foram imersos por aproximadamente um minuto em solução com álcool (70\%) para assepsia e em seguida lavados com água corrente e secados em papel toalha. Em razão das sementes de sorgo serem peletizadas não houve a necessidade de assepsia prévia.

Os testes de germinação foram realizados seguindo os mesmos procedimentos descritos anteriormente (testes iniciais de germinação), com a exceção do umedecimento do substrato (papel 'germitest'), onde foram utilizadas as soluções preparadas pela infusão dos restos vegetais de $P$. moniliformis nas diferentes concentrações $\left(25,50,75\right.$ e $\left.100 \mathrm{~g} \mathrm{~L}^{-1}\right)$, mantendo o volume de $3 \mathrm{x}$ o peso do papel, o que correspondeu a 1,55;3,10; 4,65 e 6,21 g de matéria seca 
por parcela para os respectivos tratamentos. As parcelas controle foram umedecidas normalmente com água destilada. A cada semana, durante os testes, houve necessidade de troca do substrato para novo umedecimento, seja com água destilada (controle) ou com os extratos vegetais em suas diferentes concentrações, dessa forma evitou-se alteração das concentrações pela adição de água no mesmo papel.

Foi utilizado o delineamento inteiramente casualizado com 4 repetições, sendo a parcela constituída por uma caixa 'gerbox' ou rolo de papel contendo 50 sementes uniformemente distribuídas.

Os parâmetros avaliados foram a primeira contagem de germinação (PC), no $4^{\circ}$ dia para o sorgo e $7^{\circ}$ dia para as espécies daninhas; a porcentagem final de germinação (PG), no $10^{\circ}$ dia para o sorgo e $21^{\circ}$ dia para as espécies daninhas. Foram consideradas germinadas as sementes que produziram plântulas com todas as partes essenciais visíveis (radícula, caulículo e folha primária); o índice de velocidade de germinação (IVG), de acordo com a equação de Maguire (1962): IVG $=\Sigma$ (SE / DS), onde SE: número de sementes emergidas, e DS: número de dias transcorridos após a semeadura; e o tempo médio de germinação (TMG), com o resultado expresso em dia: $\mathrm{TMG}=\Sigma(\mathrm{Ne} \mathrm{Ti}) / \Sigma \mathrm{Ne}$, onde Ti: tempo entre o início do experimento e a i-ésima observação (dia), e Ne: número de sementes que germinaram no tempo Ti (LABOURIAU, 1983).

Para o sorgo sacarino, foi determinada também a porcentagem de plântulas normais (PN), não sendo consideradas plântulas com alteração de coloração, deformações ou anomalias de acordo com Brasil (2009) e também por comparação com as plântulas das parcelas controle. Foram ainda realizadas mensurações com 10 plântulas retiradas aleatoriamente das parcelas e determinado o comprimento da parte aérea e da raiz por plântula, com auxílio de régua milimétrica. Posteriormente, as plântulas foram colocadas em sacos ' $k r a f t$ ' e levadas à estufa a $80^{\circ} \mathrm{C}$ por 24 horas e com o auxílio de uma balança analítica o material foi pesado e quantificada a massa da matéria seca por plântula. Para as plantas daninhas não foi realizado tais avaliações em razão das plântulas serem muito diminutas inviabilizando qualquer distinção entre estas.

Os dados obtidos foram inicialmente submetidos a testes de normalidade (KolmogorovSmirnov, Lilliefors, Kuiper e Watson), e quando não apresentaram a distribuição normal foram transformados pela fórmula $(\mathrm{X}+0,5)^{0,5}$ (variáveis $\mathrm{PC}$ e $\mathrm{PN}$ ) ou pelo sistema box-cox (variável TMG), sendo apresentadas as médias originais. Em seguida, foi realizada análise de variância (ANOVA) sob esquema fatorial (3 espécies x 5 concentrações) e as médias comparadas por teste de Tukey (5\%) para diferenciar as espécies e regressão polinomial para estudo do comportamento em função das concentrações do extrato vegetal. Os dados de plântulas do sorgo sacarino foram submetidos à ANOVA simples (único fator) seguida de regressão polinomial. Para auxílio nas análises foram utilizados os softwares Sisvar 5.6, Assistat 7.7 beta e Action Stat versão 3.2.60.1118. build 1 . 


\section{RESULTADOS E DISCUSSÃO}

A análise dos dados revelou efeito significativo $(p \leq 0,01)$ das concentrações do extrato aquoso para as diferentes espécies estudadas, com interação também significativa (Tabela 2), o que mostra grande influência da presença dos compostos de $P$. moniliformis na germinação e vigor destas espécies (sorgo e daninhas).

É importante ressaltar que a condição química das soluções utilizadas, principalmente pH e CE, não mascararam o efeito alelopático, já que não houve variação acentuada do pH entre os tratamentos, e a condutividade elétrica se manteve em baixos níveis (Tabela 1). De acordo com Coelho et al. (2014), estudando diferentes variedades de sorgo, só há influência da CE na germinação quando os valores ultrapassam $10 \mathrm{dS} \mathrm{m}^{-1}$, bem superior ao maior valor encontrado que foi de 3,06 dS m${ }^{-1}$ quando em concentração de $100 \mathrm{~g} \mathrm{~L}^{-1}$ (Tabela 1).

Tabela 2. Resumo da Análise de Variância (ANOVA) para os parâmetros de qualidade fisiológica de sementes de sorgo sacarino, Emilia fosbergii e Bidens pilosa, assim como para as características de plântulas do sorgo sacarino em função do extrato aquoso com restos vegetais de Pityrocarpa moniliformis. Summary of Analysis of Variance (ANAVA) for parameters of physiological quality of sorghum, Emilia fosbergii and Bidens pilosa seeds, even as for the characteristics of sorghum sorghum seedlings as a function of the aqueous extract with plant remains of Pityrocarpa moniliformis.

\begin{tabular}{|c|c|c|c|c|c|}
\hline \multicolumn{6}{|c|}{ ANOVA (Fatorial $3 \times 5$ ) } \\
\hline FV & GL & PC & PG & IVG & TMG \\
\hline \multicolumn{6}{|c|}{----------------------- Quadrado médio ----------------------- } \\
\hline Espécies & 2 & $882,00 * *$ & $1748,00 * *$ & $36,14 * *$ & $152,00 * *$ \\
\hline Ex. aquoso & 4 & $915,00 * *$ & $204,40 * *$ & $23,66^{* *}$ & $26,70 * *$ \\
\hline Esp. X Ext. & 8 & $513,00 * *$ & $113,90^{*}$ & $2,59 * *$ & $4,57 * *$ \\
\hline Erro & & 47,57 & 52,90 & 0,75 & 1,24 \\
\hline $\mathrm{CV}(\%)$ & & 64,06 & 9,12 & 15,33 & 13,27 \\
\hline \multicolumn{6}{|c|}{ ANOVA (fator único) } \\
\hline \multirow[t]{2}{*}{ FV } & GL & CPA & $\mathrm{CT}$ & MS & PN \\
\hline & & \multicolumn{4}{|c|}{ 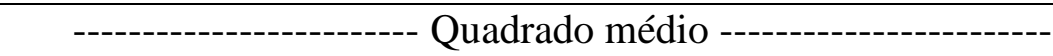 } \\
\hline Ext. aquoso & 4 & $0,7936^{\mathrm{NS}} \quad 12$ & $* * \quad 8,91^{\mathrm{NS}}$ & $0,0018^{\mathrm{NS}}$ & $2954,7 * *$ \\
\hline ERRO & 15 & 1,5243 & 6,45 & 0,0007 & 50,0 \\
\hline $\mathrm{CV}(\%)$ & & 14,36 & 16,54 & 33,04 & 28,54 \\
\hline
\end{tabular}

FV: fatores de variação; GL: grau de liberdade; PC: primeira contagem de germinação; PG: Porcentagem final de germinação; IVG: Índice de velocidade de germinação; TMG: tempo médio de germinação; CPA: comprimento de parte aérea; CR: comprimento de raiz; CT: comprimento total; MS: massa da matéria seca; PN: plântulas normais. ${ }^{* *}$ significativo a $1 \%$ de probabilidade de erro pelo teste $\mathrm{F}$; $*$ significativo a $5 \%$ de probabilidade de erro pelo teste $\mathrm{F}$; ${ }^{\mathrm{NS}}$ não significativo pelo teste $\mathrm{F}$. VF: variation factors; DF: degree of freedom; FC: first germination count; FG: final germination percentage; GSI: germination speed index; MGT: mean germination time; SL: shoot length; RL: root length; TL: total length; DM: dry matter mass; NS: normal seedlings. ** significant at $1 \%$ probability of error by the F test; * significant at $5 \%$ probability of error by the $F$ test; ${ }^{N S}$ not significant by $F$ test. 
Para efeito estatístico, a Tabela 3 apresenta as diferenças entre os valores médios da porcentagem de germinação e parâmetros de vigor para as três espécies estudadas. Quando da ausência do extrato de $P$. moniliformis (testemunha), foi observado que o sorgo apresentou uma maior porcentagem de germinação inicial, comparado às daninhas, mas se iguala ou é inferior em valores médios na porcentagem final e nos parâmetros de velocidade de germinação (IVI e tempo médio).

Tabela 3. Parâmetros de qualidade fisiológica de sementes das espécies sorgo sacarino, Bidens pilosa e Emilia fosbergii em função de diferentes concentrações do extrato aquoso de restos vegetais de Pityrocarpa moniliformis. Parameters of physiological quality of sweet sorghum, Emilia fosbergii and Bidens pilos a seeds as a function of different concentrations of the aqueous extract with plant remains of Pityrocarpa moniliformis.

\begin{tabular}{|c|c|c|c|c|c|}
\hline Conc. / & $\mathbf{0}$ & 25 & \multirow{2}{*}{$\begin{array}{c}\mathbf{5 0} \\
\mathrm{g} \mathrm{L}^{-1}\end{array}$} & 75 & \multirow[t]{2}{*}{100} \\
\hline Espécies & ---- & & & -------- & \\
\hline \multicolumn{6}{|c|}{$\mathrm{PC}(\%)$} \\
\hline Sorgo & $52,5 \mathrm{a}^{*}$ & $10,5 \mathrm{a}$ & $4,5 \mathrm{~b}$ & $0,0 \mathrm{~b}$ & $6,5 \mathrm{a}$ \\
\hline B. pilosa & $7,0 \mathrm{~b}$ & $2,0 \mathrm{~b}$ & $1,0 \mathrm{~b}$ & $4,5 \mathrm{~b}$ & $1,0 \mathrm{a}$ \\
\hline E. fosbergii & $19,0 \mathrm{~b}$ & $14,5 \mathrm{a}$ & $15,0 \mathrm{a}$ & $16,5 \mathrm{a}$ & $7,0 \mathrm{a}$ \\
\hline \multicolumn{6}{|c|}{$\mathrm{PG}(\%)$} \\
\hline Sorgo & $75,0 \mathrm{~b}$ & $76,5 \mathrm{~b}$ & $74,0 \mathrm{~b}$ & $69,5 \mathrm{a}$ & $72,0 \mathrm{~b}$ \\
\hline B. pilosa & $82,5 \mathrm{~b}$ & $78,5 \mathrm{~b}$ & $74,5 \mathrm{~b}$ & $78,0 \mathrm{a}$ & $63,5 \mathrm{~b}$ \\
\hline E. fosbergii & $95,5 \mathrm{a}$ & $92,5 \mathrm{a}$ & $95,0 \mathrm{a}$ & $78,5 \mathrm{a}$ & $91,0 \mathrm{a}$ \\
\hline \multicolumn{6}{|c|}{ IVG } \\
\hline Sorgo & $8,65 \mathrm{a}$ & $7,42 \mathrm{a}$ & $6,87 \mathrm{a}$ & $5,99 \mathrm{a}$ & $6,60 \mathrm{a}$ \\
\hline B. pilosa & $8,08 a b$ & $4,80 \mathrm{~b}$ & $3,52 \mathrm{~b}$ & $3,42 \mathrm{~b}$ & $2,37 \mathrm{c}$ \\
\hline E. fosbergii & $6,86 \mathrm{~b}$ & $6,09 a b$ & $5,77 \mathrm{a}$ & $4,41 \mathrm{~b}$ & $4,16 b$ \\
\hline \multicolumn{6}{|c|}{ TMG (dias) } \\
\hline Sorgo & $4,36 \mathrm{~b}$ & $5,27 \mathrm{~b}$ & $5,54 \mathrm{c}$ & $6,01 \mathrm{c}$ & $5,62 \mathrm{~b}$ \\
\hline B. pilosa & $6,99 \mathrm{a}$ & $9,71 \mathrm{a}$ & $11,17 \mathrm{a}$ & $12,72 \mathrm{a}$ & $13,13 \mathrm{a}$ \\
\hline E. fosbergii & $7,51 \mathrm{a}$ & $8,30 \mathrm{a}$ & $8,72 \mathrm{~b}$ & $9,65 \mathrm{~b}$ & $11,51 \mathrm{a}$ \\
\hline
\end{tabular}

PC: primeira contagem germinação; PG: porcentagem final de germinação; IVG: índice de velocidade de germinação; TMG: tempo médio de germinação. *Letras iguais na coluna não diferem estatisticamente ao nível de $5 \%$ de probabilidade de erro pelo teste de Tukey. Conc. = concentrações. FC: first germination count; FG: final germination percentage; GSI: germination speed index; MGT: mean germination time. * Equal letters in the column do not differ statistically at the 5\% probability level of error by Tukey's test. Conc. = concentrations. Source: Prepared by the authors.

Com relação às espécies daninhas, E. fosbergii se manteve superior em valores de porcentagem de germinação comparado à $B$. pilosa, chegando à valores de germinação de 95,5\% (Tabela 3). Isso pode estar relacionado à qualidade inicial do lote, onde esta espécie apresentou porcentagem de germinação um pouco superior a $B$. pilosa. Germinação rápida e eficiente é caráter inato das chamadas plantas daninhas verdadeiras, garantindo-as eficiente propagação e rápida dominação do espaço terrestre. Outras características relacionadas à propagação via sementes são a alta produção, a fácil dispersão e a ocorrência de dormência em algumas espécies (BRIGHENTI; OLIVEIRA, 2011). 
A espécie E. fosbergii é citada na literatura também por Emilia coccinea (Sims) Sweet ou ainda Emilia sagittata DC., ambos sinônimos botânicos (FLORA DO BRASIL, 2019). É uma planta daninha nativa do Brasil infestante de lavouras anuais e perenes. É importante mencionar que a literatura relata atividade antimicrobiana, antidiarreica e anti-inflamatória, caracterizando-a como planta medicinal. Este potencial é devido a presença de alcalóides e taninos advindo de seu metabolismo secundário (TEKE et al., 2007; LESSA et al., 2013). Infere-se, portanto, a existência de forte potencial alelopático, garantindo-a maior capacidade de dominação do espaço.

A espécie $B$. pilosa apresentou porcentagem final de germinação semelhante $(p \leq 0,05)$ a E. fosbergii, porém com um processo germinativo mais lento, apresentando valores inferiores para a porcentagem de primeira contagem e IVG. Na ausência do extrato e com $25 \mathrm{~g} \mathrm{~L}^{-1}$ deste, ambas as daninhas obtiveram TMG iguais estatisticamente, e com o aumento da concentração do extrato a B. pilosa aumentou o TMG sendo superior estatisticamente $(p \leq 0,05)$ às demais (Tabela 3). Esta espécie é outra importante planta daninha que se propaga exclusivamente por sementes, muito prolífica e de ciclo curto, capaz de produzir até três gerações por ano, apresenta grande plasticidade fenotípica invadindo desde áreas de olericultura até pastagens mal manejadas (LORENZI, 2008; GAZZIERO et al., 2015).

Com relação às curvas de respostas em função das concentrações do extrato, estas se revelaram significativas $(p \leq 0,01)$ em todas as variáveis estudadas. Para a porcentagem final de germinação, o efeito alelopático não se mostrou efetivo nas espécies $E$. fosbergii e sorgo sacarino. Apenas para B. pilosa o efeito foi verificado, no qual perdeu linearmente $18,5 \%$ de germinação final, comparando a testemunha com a concentração máxima de $100 \mathrm{~g} \mathrm{~L}^{-1}$ (Figura $1 \mathrm{~B})$.

De modo geral, as espécies foram prejudicadas pelo extrato principalmente quanto ao vigor de sementes, pelas evidências ao se analisar as variáveis PC, IVG e TMG. Como pode ser visualizado na Figura 1, gráfico A, o sorgo sacarino foi a espécie que mais foi suscetível aos tratamentos. Verificou-se uma parábola $(p \leq 0,01)$ com queda inicial brusca da porcentagem chegando a anular a germinação inicial quando da dose de $52,2 \mathrm{~g} \mathrm{~L}^{-1}$. A germinação de sorgo também foi prejudicada em ocasião da presença do extrato aquoso de outra importante espécie nativa do bioma Caatinga, o cumaru (Amburana cearensis (Allemão) A.C.Sm.), sendo o efeito alelopático atribuído ao composto cumarina (SILVA et al., 2006), molécula química também presente na espécie objeto do presente trabalho, a $P$. miniliformis (SILVA, 2013). O cumaru também se mostrou importante para inibir em 99\% a germinação de sementes de Amaranthus deflexus L. (LESSA et al., 2017), planta daninha importante principalmente em cultivos perenes, mas também encontrada em lavouras anuais (LORENZI, 2008). 
(A)

(B)
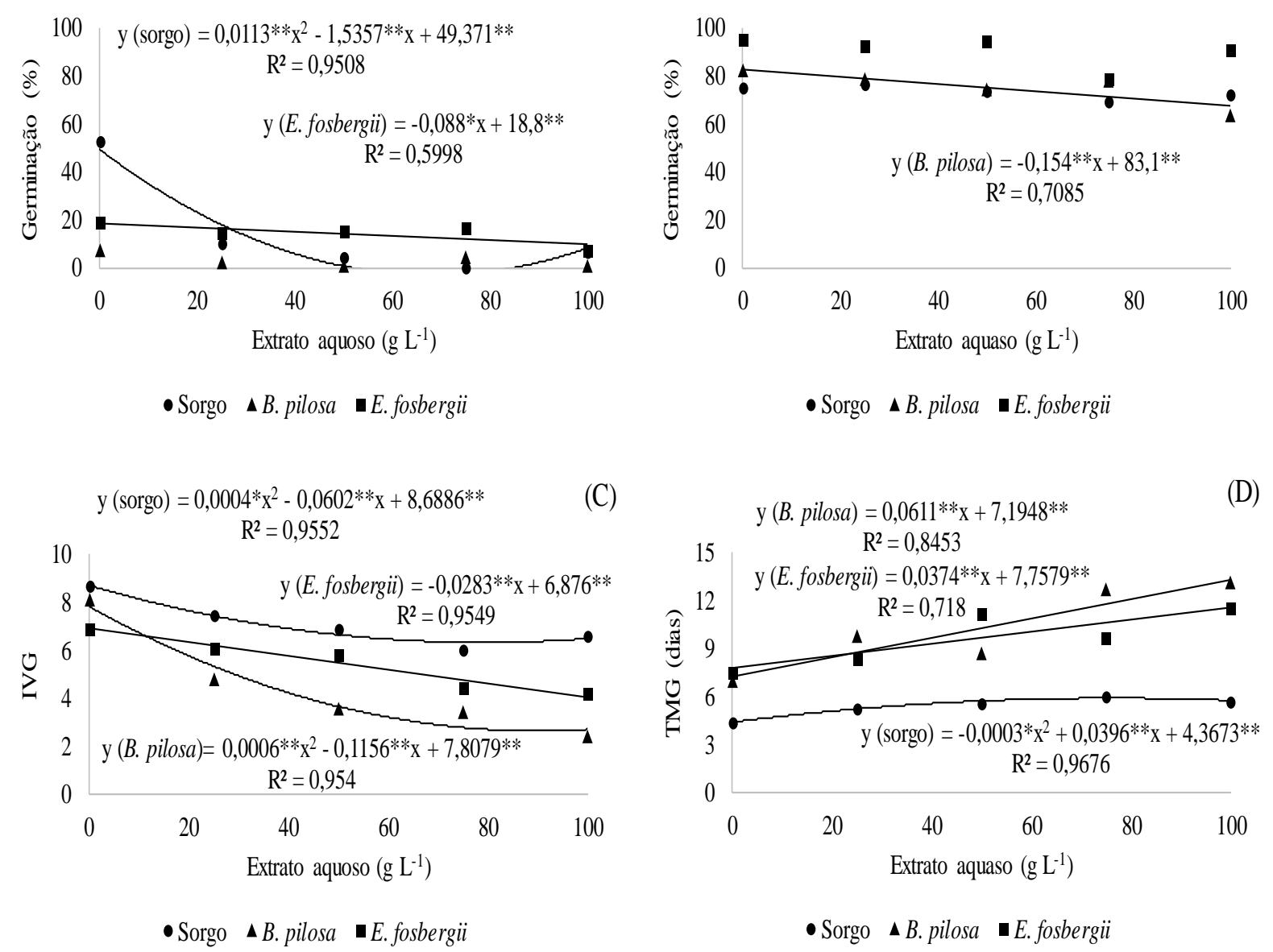

** significativo a $1 \%$ de probabilidade de erro pelo teste $\mathrm{t} ; *$ significativo a $5 \%$ de probabilidade de erro pelo teste t. ** significant at $1 \%$ probability of error by the t test; * significant at $5 \%$ probability of error by the $t$ test.

Figura 1. Primeira contagem de germinação (A), porcentagem final de germinação (B), índice de velocidade de germinação - IVG (C) e tempo médio de germinação - TMG (D) para as espécies sorgo sacarino, Bidens pilosa e Emilia fosbergii em função do extrato aquoso obtido pela infusão de restos vegetais de Pityrocarpa moniliformis. First germination count $(A)$, Final germination porcentage $(B)$, germination speed index $(C)$ and mean germination time (D) for sweet sorghum, Bidens Pilosa and Emilia fosbergii as a function of the aqueous extract with plant remains of Pityrocarpa moniliformis.

Independentemente da espécie, a alelopatia foi mais pronunciada no vigor das sementes, aqui representado pela velocidade do processo germinativo. $O$ índice de velocidade de germinação decaiu significativamente $(p \leq 0,05)$ com o aumento da concentração do extrato aquoso (Figura 1, Gráfico C). O sorgo sacarino e a planta daninha B. pilosa apresentaram comportamento descrito pelo modelo quadrático com os menores valores encontrados para 75,2 e 96,3 $\mathrm{g} \mathrm{L}^{-1}$ (ponto mínimo das parábolas) respectivamente. O declínio no IVI em comparação à testemunha foi, portanto, de 27,7 e 71,3\% respectivamente, para o sorgo e $\mathrm{B}$. pilosa. Para E. fosbergii o IVI decresceu $41,1 \%$ de forma linear quando se compara a testemunha ao tratamento de $100 \mathrm{~g} \mathrm{~L}^{-1}$ (Figura 1, Gráfico C). 
O retardamento no processo germinativo foi evidenciado também quanto ao tempo médio de germinação (TMG). As espécies daninhas apresentaram um acréscimo de 6 e 4 dias para B. pilosa e E. fosbergii, respectivamente, quando analisando o comportamento linear entre a testemunha e a concentração máxima do extrato (Figura 1, Gráfico D). O sorgo sacarino, diferentemente às daninhas, apresentou significativamente $(p \leq 0,05)$ um modelo quadrático na regressão, revelando TMG máximo calculado de 5,6 dias com $66 \mathrm{~g} \mathrm{~L}^{-1}$ (Figura 1, Gráfico D).

Com os resultados apresentados até então, a espécie $B$. pilosa se mostrou mais suscetível ao efeito alelopático causado pelo extrato de $P$. moniliformis em comparação às demais espécies objeto do estudo. A espécie perdeu 18,5\% de germinação e 71\% em índice de velocidade, com um tempo médio passando de 7 dias (testemunha) para 13 dias sob a concentração do extrato de $100 \mathrm{~g} \mathrm{~L}^{-1}$. B. pilosa apresentou relação alelopática também sob o extrato da planta cultivada canola a qual promoveu influência negativa na germinação dos aquênios (RIZZARDI et al., 2008). Por outro lado, em trabalho de Araújo et al. (2010) estudando a espécie Crotalaria juncea $\mathrm{L}$. concluiu existência de alelopatia sobre a germinação dos aquênios de B. pilosa, com efeito benéfico a esta, aumentando o número de sementes germinadas. Nota-se a importância de conhecer bem as interações interespecíficas afim de estabelecer os componentes vegetais adequados em sistemas de consorcio ou rotação para não prejudicar o crescimento da cultura de interesse, mas que possa mitigar a infestação de certas populações de plantas daninhas e nunca o contrário.

O presente trabalho analisou ainda as plântulas do sorgo sacarino para a determinação dos aspectos de crescimento e da porcentagem de plântulas normais, esta última, característica válida tecnologicamente para a contabilização da germinação em espécies cultivadas, de acordo com as Regras para Análise de Sementes (BRASIL, 2009). A variável CPA não obteve significância pelo teste $\mathrm{F}$ na análise de variância $(p \geq 0,05)$, mesmo resultado encontrado para as variáveis CT e MS (Tabela 2). Em contrapartida, o crescimento do sistema radicular quando analisado individualmente revelou um modelo quadrático significativo $(p \leq 0,01)$ apontando a concentração de $69,1 \mathrm{~g} \mathrm{~L}^{-1}$ como a que proporcionou o menor tamanho de radícula $(5,4 \mathrm{~cm})$, uma redução de 4,3 cm em comparação à testemunha (Figura 2, Gráfico A).

A diminuição do tamanho da raiz primária veio associada a modificações morfológicas quando comparadas às plântulas testemunhas, com deformações evidentes nos coleóptilos e radículas das plântulas submetidas a presença do extrato de $P$. miniliformis, com partes retorcidas e desproporcionais, e maior surgimento de raízes secundárias, acentuando-se tais características quando do aumento da concentração do extrato (Figura 3); ao ponto de não mais haver plântulas normais no teste de germinação (Brasil, 2009) quando da concentração de 74,3 g L L $^{-1}$ (Figura 2, Gráfico B). De acordo com BRASIL (2009) as plântulas com deformações são consideradas dentro da categoria de plântulas anormais, ou seja, aquelas que não mostram potencial para continuar seu desenvolvimento e dar origem a plantas normais. 


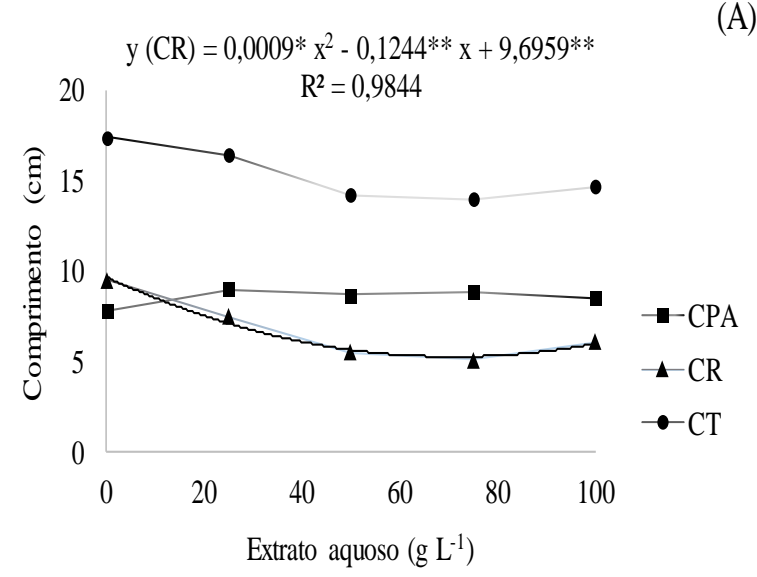

(A)

(B)

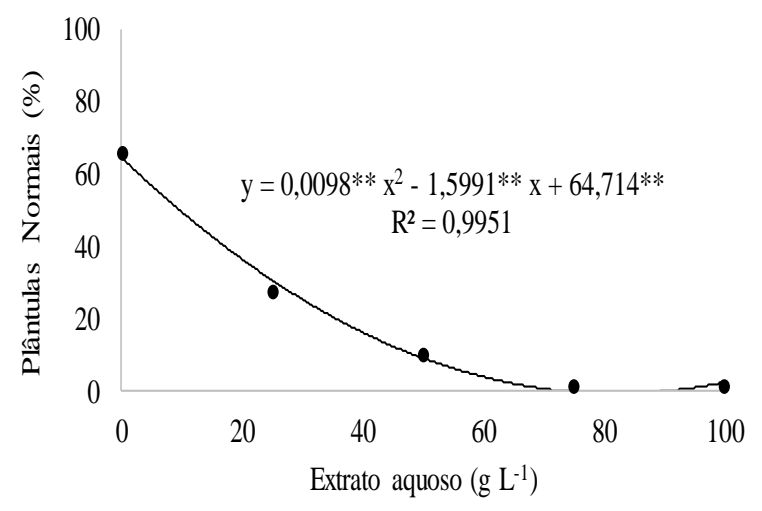

** significativo a $1 \%$ de probabilidade de erro pelo teste $\mathrm{t}$; $*$ significativo a $5 \%$ de probabilidade de erro pelo teste t. ** significant at $1 \%$ probability of error by the t test; * significant at $5 \%$ probability of error by the $t$ test.

Figura 2. Comprimento da parte aérea, da raiz e total (A) e porcentagem de plântulas normais (B) de sorgo sacarino em função do extrato aquoso obtido pela infusão de restos vegetais de Pityrocarpa moniliformis. Shoot, root and total length (A) and normal seedlings percentage (B) of sweet sorghum as a function of the aqueous extract with plant remains of Pityrocarpa moniliformis.

Ferreira e Áquila (2000) relataram que a avaliação do crescimento e desenvolvimento das plântulas se torna um instrumento valioso de diagnóstico, afirmando que o aparecimento de plântulas anormais é induzido pela presença de aleloquímicos. Em relato de Souza Filho (2014) sobre o tema alelopatia, este autor comenta que uma vez absorvidos pela planta-alvo (receptora), os aleloquímicos passam a afetar diferentes processos fisiológicos e metabólicos, em diferentes intensidades dependendo principalmente da concentração do composto em nível celular. $\mathrm{O}$ autor cita possíveis ações dos aleloquímicos que explicariam seus efeitos, como perturbações na membrana plasmática, interações com reguladores de crescimento (hormônios), ação sobre a divisão e expansão celular e respiração. Tais informações parecem explicar as modificações evidenciadas, principalmente nas maiores concentrações estudadas, 75 e $100 \mathrm{~g} \mathrm{~L}^{-1}$ (Figura 3).

Além do retraimento e torções das partes essenciais nas plântulas do sorgo, verificou-se também um padrão de crescimento direccionalmente aleatório, revelando efeito no tropismo regular de estabelecimento das plântulas, quando do tratamento com $100 \mathrm{~g} \mathrm{~L}^{-1}$ do extrato (Figura 3). Este tratamento promoveu a existência de plântulas com parte aérea e raiz desenvolvendo-se no mesmo sentido, evidenciando uma anomalia. $\mathrm{O}$ tropismo influencia o crescimento inicial da planta jovem, de acordo com estímulos ambientais como gravidade, luz e toque, e é o responsável pelo crescimento direcional de sentido oposto da parte aérea e raiz. O tropismo condicionado pela gravidade (gravitropismo) possibilita o crescimento do caule para cima enquanto da raiz para baixo, assim como o fototropismo condiciona o crescimento do caule em direção à fonte de luz e da raiz para longe da luz (TAIZ et al., 2017). Ecologicamente necessários, estes fenômenos garantem o processo de fotossíntese para a parte aérea e também a adequada fixação ao solo/substrato e extração de nutrientes para as raízes. 


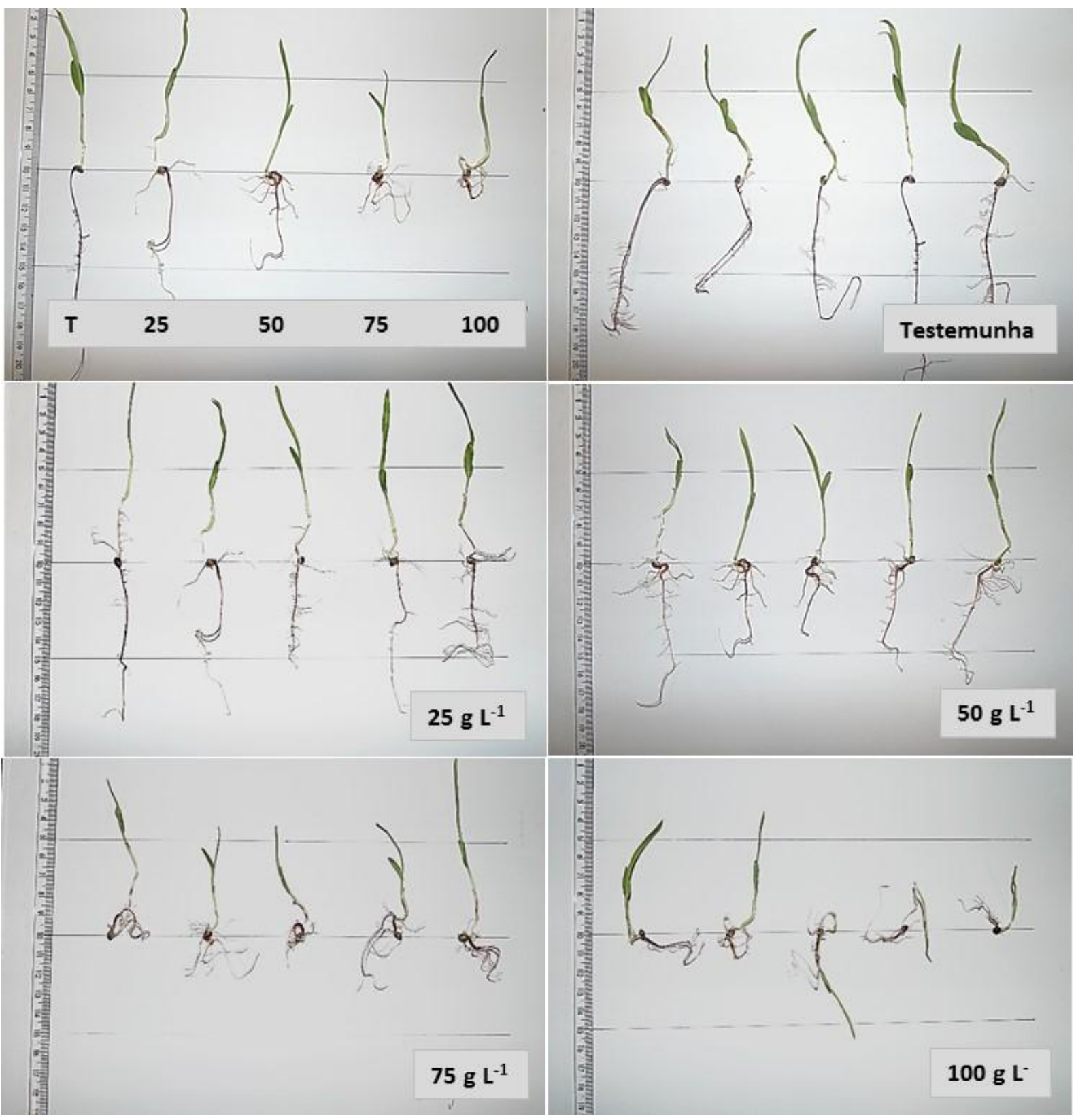

Figura 3. Plântulas de sorgo sacarino oriundas de testes de germinação utilizando diferentes concentrações do extrato aquoso de restos vegetais de Pityrocarpa moniliformis. Sweet sorghum seedlings from the germination tests using different concentrations of the aqueous extract with plant remains of Pityrocarpa moniliformis.

A posição das parcelas experimentais (rolos de papel verticalmente posicionados) dentro das câmeras de germinação possibilita o crescimento regular das plântulas como evidenciado pelas parcelas testemunhas, descartando fatores externos de interação a não ser pela ação efetiva do extrato (fonte única de variação). Esta alteração ao nível de tropismo pode ser explicada em parte pelas interações do(s) aleloquímico(s) presente(s) no extrato de P. miniliformis com os reguladores (hormônios) nas células meristemáticas das plântulas de sorgo, interação esta mencionada anteriormente. Este caso sugere relação com a auxina, visto que este regulador está associado ao crescimento vegetal como um todo e sua sinalização funciona praticamente em todos os aspectos do desenvolvimento, incluindo o fenômeno do 
tropismo, tendo em vista que seu funcionamento é regulado pelo fluxo do hormônio auxina no ápice do coleóptilo e na coifa da raiz (TAIZ et al., 2017).

Em razão dos resultados, apesar do efeito prejudicial encontrado para o estabelecimento das plantas daninhas estudadas em função do extrato de $P$. miniliformis, fica evidenciado o também prejuízo para o estabelecimento da espécie cultivada sorgo sacarino, o que sugere que esta espécie florestal da Caatinga apresenta potencial para possíveis estratégias de controle de plantas daninhas, mas não pode estar associada a cultivos de sorgo sacarino da variedade BRS 506 em possíveis sistemas de integração. Recomenda-se, portanto, que em áreas de cultivo deste tipo de sorgo próximas de formações florestais naturais ou áreas recuperadas devem ser monitoradas para constante limpeza, eliminando possíveis restos vegetais da catanduva dentro do plantel.

\section{CONCLUSÃO}

O extrato aquoso feito a partir de folhas e ramos da espécie nativa do bioma Caatinga Pityrocarpa moniliformis (Benth.) Luckow \& R.W. Jobson apresenta ação alelopática sobre a germinação das espécies daninhas Emilia fosbergii Nicolson e Bidens pilosa L. e também da espécie cultivada sorgo sacarino (variedade BRS 506), promovendo diminuição da velocidade do processo germinativo das três espécies e menor número de sementes germinadas para $\mathrm{B}$. pilosa.

O extrato de $P$. moniliformis apresenta ação alelopática também no crescimento das plântulas do sorgo sacarino, promovendo deformações na raiz primária e coleóptilo com consequente diminuição no número de plântulas normais.

\section{AGRADECIMENTO}

Ao Centro de Referência em Recuperação de Áreas Degradadas (CRAD) da Universidade Federal do Vale do São Francisco pelo apoio material e intelectual necessários à realização deste trabalho.

\section{REFERÊNCIAS BIBLIOGRÁFICAS}

ARAÚJO, E. O.; ESPÍRITO SANTO, C. L.; SANTANA, C. N. Potencial alelopático de extratos vegetais de Crotalaria juncea sobre a germinação de plantas daninhas. Revista Brasileira de Agroecologia, Rio de Janeiro, v. 5, n. 2, p.109-115, 2010. Disponível em: <http://orgprints.org/24489/1/Ara\%C3\%BAjo_Potencial.pdf>. Acesso em: 26 set. 2018.

AZEREDO, G. A.; PAULA, R. C.; VALERI, S. V.; MORO, F. V. Superação de dormência de sementes de Piptadenia moniliformis Benth. Revista Brasileira de Sementes, Londrina, v. 32, n. 2, p.49-58, 2010. Disponível em: 〈http://www.scielo.br/pdf/rbs/v32n2/v32n2a06.pdf>. Acesso em: 26 set. 2018.

BALBINOT JÚNIOR, A. A.; MORAES, A.; VEIGA, M.; PELISSARI, A.; DIECKOW J. Integração lavoura-pecuária: intensificação de uso de áreas agrícolas. Ciência Rural, Santa 
Maria, v. 39, n. 6, p.1925-1933, 2009. Disponível em: <http://www.scielo.br/pdf/cr/2009nahead/a229cr838.pdf>. Acesso em: 20 ago. 2018.

BENEDITO, P. C. Armazenamento e viabilidade de sementes de catanduva (Piptadenia moniliformis Benth). 2010. 63 f. Dissertação (Mestrado em Fitotecnia) - Universidade Federal Rural do Semi-Árido, Mossoró, 2010.

BRASIL. Ministério da Agricultura, Pecuária e Abastecimento. Secretaria de Defesa Agropecuária. Regras para análises de sementes. Brasília, DF: Mapa/ACS, 2009. 395 p.

BRIGHENTI, A. M.; OLIVEIRA, M. F. Biologia de plantas daninhas. In: OLIVEIRA JÚNIOR., R. S.; CONSTANTIN, J.; INOUE, M. H. (Ed.) Biologia e manejo de plantas daninhas. Curitiba: Omnipax, 2011. cap. 1, p. 1-36.

COELHO, D. S.; SIMÕES, W. L.; MENDES, A. M. S.; DANTAS, B. F.; RODRIGUES, J. A. S.; SOUZA, M. A. Germinação e crescimento inicial de variedades de sorgo forrageiro submetidas ao estresse salino. Revista Brasileira de Engenharia Agrícola e Ambiental, Campina Grande, v. 18, n. 1, p.25-30, 2014. Disponível em: <http://www.scielo.br/pdf/rbeaa/v18n1/v18n1a04.pdf>. Acesso em: 12 ago. 2018.

DURÃES, F. O. M.; MAY, A.; PARRELLA, L. A. C. Sistema agroindustrial do sorgo sacarino no Brasil e a participação público-privada: oportunidades, perspectivas e desafios. Sete Lagoas: Embrapa Milho e Sorgo, 2012. 76 p. (Documentos, 139). Disponível em: $\quad<$ https://www.embrapa.br/busca-de-publicacoes/-/publicacao/933001/sistemaagroindustrial-do-sorgo-sacarino-no-brasil-e-a-participacao-publico-privada-oportunidadesperspectivas-e-desafios>. Acesso em: 10 abr. 2019.

FERREIRA, A. G.; AQUILA, M. E. A. Alelopatia: Área emergente da ecofisiologia. Revista Brasileira de Fisiologia Vegetal, Campinas, v. 12, Edição Especial, p.175-204, 2000. Disponível em: <http://www.lpv.esalq.usp.br/sites/default/files/8\%20-\%20Semana\%204\%20$\% 20$ Alelopatia\%20na\%20agricultura\%20-\%20referencia\%201eitura\%20-

\%20referencia\%20leitura.pdf $>$. Acesso em: 20 set. 2018.

FLORA DO BRASIL. Flora do Brasil 2020 em construção. Jardim Botânico do Rio de Janeiro. Disponível em: <http://floradobrasil.jbrj.gov.br/>. Acesso em: 10 abr. 2019.

GAZZIERO, D. L. P.; LOLlATO, R. P.; BRIGHENTI, A. M.; PITELli; R. A.; VOLL, E. Manual de identificação e plantas daninhas da cultura da soja. 2 ed. Londrina: Embrapa soja, 2015, 126 p. (Documentos, 274)

LABOURIAU, L. G. A germinação das sementes. Washington: Secretaria Geral da Organização dos Estados Americanos, 1983. 174 p.

LESSA, B. F. T.; FERREIRA, V. M.; ARAÚJO NETO, J. C.; SOUZA, R. C. Germinação de sementes de Emilia coccinea (Sims) G. DON em função da luminosidade, temperatura, armazenamento e profundidade de semeadura. Semina: Ciências Agrárias, Londrina, v. 1, n. 34, p.3193-3204, 2013. Disponível em: <http://www.redalyc.org/articulo.oa?id=445744137007>. Acesso em: 20 ago. 2018.

LESSA, B. F. T.; SILVA, M. L. S.; BARRETO, J. H. B.; OLIVEIRA, A. B. Efeitos aleopáticos de extratos aquosos de folhas de Amburana cearensis e Plectranthus barbatus na 
germinação de Amaranthus deflexus. Revista de Ciências Agrárias, Lisboa, v. 40, n. 1, p. 79-86, 2017. Disponível em: <http://www.scielo.mec.pt/pdf/rca/v40n1/v40n1a10.pdf>. Acesso em: 14 set. 2018.

LORENZI, H. Plantas daninhas do Brasil: terrestres, aquáticas, parasitas e tóxicas. 4. ed. Nova Odessa: Instituto Plantarum, 2008. 640 p.

MAGUIRE, J. D. Speed of germination-aid in selection and evaluation for seedling emergence and vigor. Crop Science, Madison, v. 2, n. 1, p.176-177, 1962.

PITELLI, R. A. O termo planta-daninha. Planta Daninha, Viçosa, v. 33, n. 3, p.622-623, 2015.

RIBEIRO, C. V. C.; KAPLAN, M. A. C. Tendências evolutivas de famílias produtoras de cumarinas em Angiospermae. Química Nova, São Paulo, v. 25, n. 4, p.533-538, 2002. Disponível em: 〈http://www.scielo.br/pdf/qn/v25n4/10524.pdf〉. Acesso em: 26 set. 2018.

RIZZARDI, A.; RIZZARDI, M. A.; LAMB, T. D.; JOHAN, L. B. Potencial alelopático de extratos aquosos de genótipos de canola sobre Bidens pilosa. Planta Daninha, Viçosa, v. 26, n. 4, p.717-724, 2008. Disponível em: <http://www.scielo.br/pdf/pd/v26n4/02.pdf>. Acesso em: 26 set. 2018.

SILVA, A. A.; SILVA, J. F. Tópicos em manejo de plantas daninhas. Viçosa, MG: Universidade Federal de Viçosa, 2007. 367 p.

SILVA, M. F. S. Estudo químico e avaliação da atividade antibacteriana de Pityrocarpa moniliformis (Benth) Luckon \& R. W. Jobson (Fabaceae). 2013. 154 f. Dissertação (Mestrado em Recursos Naturais do Semiárido) - Universidade Federal do Vale do São Francisco, Petrolina, 2013.

SILVA, W. A.; NOBRE, A. P.; LEITES, A.P.; SILVA, M. S. C.; LUCAS, R. C.; RODRIGUES, O. G. Efeito alelopático de extrato aquoso de Amburana cearensis A. Smith na germinação e crescimento de sementes de sorgo (Sorghum bicolor L.). Agropecuária Científica no Semi-árido, Patos, v. 2, n. 1, p.48-54, 2006. Disponível em: <http://revistas.ufcg.edu.br/acsa/index.php/ACSA/article/view/22/pdf>. Acesso em: 20 set. 2018.

SOUZA FILHO, A. P. S. Alelopatia: princípios básicos e mecanismos de interferências. In: MONQUERO, P. A. (Org.) Aspectos da biologia e manejo das plantas daninhas. São Carlos: RiMa, 2014. 430 p.

TAIZ, L.; ZEIGER, E.; MOLLER, I. M.; MURPHY, A. Fisiologia e desenvolvimento vegetal. 6. ed. Porto Alegre: Artmed, 2017. 858 p.

TEKE, G. N.; KUIATE, J. R.; NGOUATEU, O. B.; GATSING, G. Antidiarrhoeal and antimicrobial activities of Emilia coccinea (Sims) G. Don extracts. Journal of Ethnopharmacology, Philadelphia, v. 112, n. 2, p.278- 283, 2007. Disponível em: <https://www.researchgate.net/publication/6393994_Antidiarrhoeal_and_antimicrobial_activi ties_of_Emilia_coccinea_Sims_G_Don_extracts>. Acesso em: 18 ago. 2018. 